\title{
Antibiotic heteroresistance in Mycobacterium tuberculosis isolates: a systematic review and meta-analysis
}

Mao Ye ${ }^{1}$, Wen Yuan ${ }^{2}$, Leila Molaeipour ${ }^{3}$, Khalil Azizian ${ }^{4^{*}}$, Alireza Ahmadi ${ }^{5,6}$ and Ebrahim Kouhsari ${ }^{5,6,7^{*}}$

\begin{abstract}
Background: Mycobacterium tuberculosis (MTB) is responsible for tuberculosis; that continues to be a public health threat across the globe. Furthermore, increasing heteroresistance (HR)-the presence of resistant and susceptible isolates among MTB strains- has been reported from around the world. This phenomenon can lead to full resistance development and treatment failure.
\end{abstract}

Methods: We systematically searched the relevant studies in PubMed, Scopus, and Embase (Until October 21, 2020). The study outcomes revealed the weighted pooled prevalence of antibiotic HR in MTB isolates with subgroup analysis by year, quality of study, and heteroresistance detection method.

Results: A total of 38 studies which had investigated MTB isolates were included in the meta-analysis. Geographically, the highest number of studies were reported from Asia $(n=24)$, followed by Africa $(n=5)$. Nineteen studies reported HR to isoniazid, with a weighted pooled prevalence of 5\% (95\% Cl 0-12) among 11,761 MTB isolates. Also, there is no important trend for the subgroup analysis by the study period (2001-2014 vs 2015-2017 vs 2018-2020). HR to rifampin was reported in 17 studies, with a weighted pooled prevalence of $7 \%(95 \% \mathrm{Cl} 2-14)$ among $3782 \mathrm{MTB}$ isolates. HR to fluoroquinolone and ethambutol were reported in 12 and 4 studies, respectively, with weighted pooled prevalence of $10 \%$ and $1 \%$ among 2153 and 1509 MTB isolates, correspondingly.

Conclusion: Based on our analysis, HR in MTB isolates with different frequency rate is present worldwide. Thus, the selection of appropriate and reliable methods for HR detection is crucial for TB eradication.

Keywords: Drug resistance, Heteroresistance, Isoniazid, Rifampin, Fluoroquinolones

\section{Introduction}

Mycobacterium tuberculosis (MTB) is responsible for tuberculosis (TB), one of the oldest recognized infections and top 10 causes of death among infectious agents in mankind. Every year, 10 million people are infected

\footnotetext{
*Correspondence: kh.azizian@sirums.ac.ir; dr.kouhsari@goums.ac.ir

${ }^{4}$ Department of Clinical Microbiology, Sirjan School of Medical Sciences, P.O. Box 78169-16338, Sirjan, Iran

${ }^{7}$ Laboratory Sciences Research Center, Faculty of Paramedical Sciences, Golestan University of Medical Sciences, Negative Floor 1, Gorgan-Sari Road, P.O. Box: 4918936316, Gorgan, Golestan Province, Iran

Full list of author information is available at the end of the article
}

with this bacterium worldwide [1, 2]. Between 2018 and 2020, 40 million new cases of TB were detected [3]. Globally, more than 1.2 million deaths related to TB infection occurred in HIV-negative (1.1-1.3 million) and HIV-positive $(2,08,000)$ people during 2019 [3]. Therefore, TB still is, as it has always been, a serious threat to public health.

Isoniazid (INH), rifampin (RIF), fluoroquinolones (FQs), and ethambutol (EMB) are the most effective drugs/drug classes in the standard TB treatment protocol. Not only, the emergence of drug resistance has become an alarming global problem [4] imposing a significant impact on the circulation of $M$. tuberculosis across the world, but also the resistant isolates are original author(s) and the source, provide a link to the Creative Commons licence, and indicate if changes were made. The images or other third party material in this article are included in the article's Creative Commons licence, unless indicated otherwise in a credit line to the material. If material is not included in the article's Creative Commons licence and your intended use is not permitted by statutory regulation or exceeds the permitted use, you will need to obtain permission directly from the copyright holder. To view a copy of this licence, visit http://creativecommons.org/licenses/by/4.0/. The Creative Commons Public Domain Dedication waiver (http://creativeco mmons.org/publicdomain/zero/1.0/) applies to the data made available in this article, unless otherwise stated in a credit line to the data. 
considered the main barrier to TB control and its eradication. Every year, nearly half a million people developed rifampin-resistance and multidrug-resistant TB (MDR-TB; resistant to at least INH and RIF) [5]. Extensively drug-resistant MTB (XDR-TB) is more menacing than MDR; XDR-TB strains are defined as resistant to INH, RIF, FQs, and one aminoglycoside injectable agent. In 2018, 14,000 XDR-TB strains were isolated worldwide [6]. However, the prevalence of drug-resistant TB is unknown [7].

In many cases, detection of MTB drug-resistant isolates in clinical samples is difficult since drug-susceptible and drug-resistant isolates coexist $[8,9]$, which may result in masking drug-resistant isolates by drug-susceptible ones. This phenomenon referred to as heteroresistance (HR) [10] is common in MTB and considered one of the major steps in the development of drug-resistance in bacterial isolates [11]. HR may arise from a mixed infection, when resistant and susceptible strains infect a person at the same time, or while single clone changes from a susceptible strain to resistant by undergoing genetic mutation under antibiotic pressure [12].

In term of clonality, both of these phenomena are classified as polyclonal HR. Although the susceptible and resistant strains are available in polyclonal HR but resistant strains are not seen when pure clones are analyzed by conventional methods. On the other hand, origin of heterogeneity could be a single clone that has both susceptible and resistant populations and considered monoclonal HR. In contrast to previous cases, in monoclonal HR, the HR phenotype is detectable when pure clones are analyzed [12]. Some studies rejected correlation between HR and treatment failure [13, 14], nevertheless several other studies and increasing evidence linked HR and treatment failure in different bacteria $[15,16]$. Moreover, $\operatorname{HR}$ has been described for several antibiotics and it is responsible for limited treatment options and also increasing rates of treatment failure in TB patients [17]. Since, HR frequency rates of MTB isolates are not very well documented, the main aim of this review and meta-analysis is to bring a comprehensive data analysis on the prevalence of heteroresistant MTB against commonly used antimicrobial agents together, including INH, RIF, FQs, and EMB. To the best of our knowledge, our meta-analysis describes the first cross study report on the prevalence of $\mathrm{HR}$ in MTB isolates.

\section{Methods \\ Guidelines}

This review is reported accordant with the preferred reporting items for systematic reviews and meta analyses guidelines (PRISMA) [18].

\section{Search strategy and study selection}

MEDLINE (PubMed), Scopus, and Embase were searched for relevant articles (Until 21, October 2020) by using the following keywords: "Mycobacterium tuberculosis" or "M. tuberculosis" or "MTB" or "tuberculosis" or "TB") AND ("heteroresistance" or "heteroresistance" or "heteroresistant" or "hetero-resistant") in the Title/Abstract/Keywords fields. No limitation was used while searching databases, but inclusion of the study in our full analysis required at least the abstract to be available in English. The records found through database searching were merged and the duplicates were removed using EndNote X7 (Thomson Reuters, New York, NY, USA).

\section{Selection criteria and data extraction}

Three reviewers (AKH, LM, EK) screened all titles and abstracts independently and excluded irrelevant data, then they independently assessed the remaining articles for inclusion. Discrepancies were resolved by discussion and a fourth author (EK) acted as arbiter. The information extracted from each study included was (1) author, (2) publication year, (3) type of samples (pulmonary or extrapulmonary), (4) number of isolates, (5) the method of heteroresistance detection [line-probe assay (LPA), sequencing-based methods, and other], and (6) heteroresistance rates (Additional file 2). Studies were excluded if they met the following conditions: (1) HR were not clearly reported; or (2) data on HR were from a meta-analysis and/or systematic review, non-original research, or conference abstract.

\section{Quality assessment}

The quality of the included studies was assessed by 2 reviewers (AKH, EK) independently, using an adapted version of the tool proposed by the Newcastle-Ottawa assessment scale for cross-sectional studies [19]. A score ranging from 0 to 7 points was attributed to each study ( 7 points: high quality, $\leq 6$ points: low quality). A third reviewer (LM) acted as an arbiter adjudicated in any cases where there was disagreement.

\section{Definitions}

HR refers to the occurrence of the populations of both drug-susceptible and drug-resistant isolates within the same clinical sample $[20,21]$.

\section{Statistical analysis}

To analyse and combine the results of different studies, in each study, the prevalence of HR was considered a binomial distribution and its standard error was calculated by this distribution. Heterogeneity of studies was 
assessed using Cochran's $\mathrm{Q}$ test and $\mathrm{I}^{2}$ index. Due to the heterogeneity of the studies, a random-effects model was used in the meta-analysis. Sensitivity analysis was used to investigate the heterogeneity sources between studies. Analysis was performed using Stata/SE software, v.14 (StataCorp, College Station, TX). All statistical interpretations were reported on a $95 \%$ confidence interval (CI) basis.

\section{Study outcome}

The main outcome of the study was the weighted pooled prevalence of HR to INH, RIF, FQs, and EMB in MTB isolates. A subgroup analysis was performed as; (1) HR method, (2) year of publication (2001-2014, 2015-2017, and 2018-2020), and (3) the quality of the studies (high quality and low quality).

\section{Results}

Results of the systematic literature search

Thirty-eight studies [1, 4, 11, 22-56] comprising 19,205 MTB isolates were included in this systematic review and meta-analysis (Fig. 1, Additional file 2). All 38 studies had a cross-sectional design. Geographically, the HR rates were reported from Asia $(\mathrm{n}=24)$, Africa $(\mathrm{n}=5)$, and Europe $(\mathrm{n}=3)$, (see Additional file 2). The studies included in this meta-analysis evaluated HR to isoniazid, rifampin, fluoroquinolones, and ethambutol.

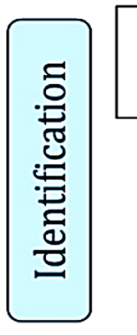

Records identified through database searching $(n=875)$

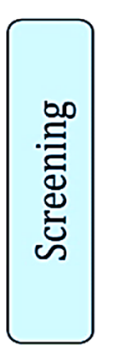

Records excluded after duplicates, titles and abstract review $(n=795)$

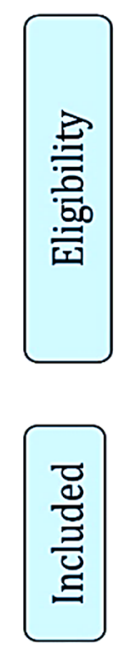

Full-text articles assessed for eligibility

$(n=80)$

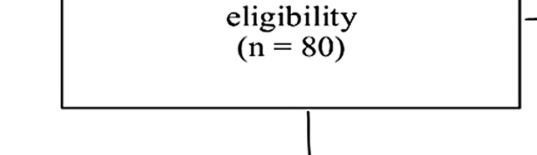

Studies included in qualitative synthesis

$(n=38)$

Studies included in quantitative synthesis (meta-analysis)

$(\mathrm{n}=38)$
Full-text articles excluded, with reasons;

- Meta-analysis, Review, conference abstract and non-relevant data or no data for heteroresistance $(n=42)$

Fig. 1 Flow chart of study selection 


\section{Meta-analysis results}

Isoniazid

HR to INH was reported in 19 studies, with a weighted pooled prevalence of 5\% (95\% CI 0-12) among 11,761 MTB isolates; a substantial heterogeneity was $\mathrm{I}^{2}=$ 99.42\% (Table 1). Sensitivity analysis was performed based on the quality of the articles, HR assay, and the year of the study. To analyze the trends for changes in the prevalence of HR to INH in more recent years, we performed a subgroup analysis for three periods (2001-2014, 2015-2017, and 2018-2020) (Table 1, Additional file 1). However, there is no important trend for the subgroup analysis by the mentioned study period (2001-2014 vs $2015-2017$ vs $2018-2020)$. LPA $(n=16)$ and sequencing-based methods $(n=2)$ were the most frequent HR methods. The prevalence of $\mathrm{HR}$ to $\mathrm{INH}$ was 5\% (95\% CI 1-15) using LPA, 0\% (95\% CI 0-1) using sequencing-based methods, and 1\% (95\% CI 0-6) using other-methods (e.g., RT-PCR) (Table 1).

\section{Rifampin}

HR to RIF was reported in 17 studies, with a weighted pooled prevalence of $7 \%$ (95\% CI $\left.2-14 ; \mathrm{I}^{2}=97.59 \%\right)$ among 3782 MTB isolates (Table 1). Sensitivity analysis was performed based on the quality of the articles, HR assay, and the year of the study. The prevalence of HR to RIF was found to be $12 \%$ (95\% CI 3-26) during 2001-2014, dropping to $2 \%$ (95\% CI 1-4) in 2015-2017, but growing back to $10 \%$ in $2018-2020$ (95\% CI 1-28) (Table 1; Additional file 1). LPA $(\mathrm{n}=9)$ and sequencing-based methods $(n=6)$ were the most frequent HR methods. The prevalence of HR to RIF using LPA was $9 \%$ (95\% CI 2-20), 6\% (95\% CI 0-16) using sequencing-based

Table 1 Prevalence of antibiotic heteroresistance in M. tuberculosis isolates based on quality, publication year, and heteroresistant assay

\begin{tabular}{|c|c|c|c|c|c|c|c|}
\hline Antibiotic & Category & Subcategory & No. of studies & $\begin{array}{l}\text { No. of } \\
\text { heteroresistant } \\
\text { isolates }\end{array}$ & $\begin{array}{l}\text { No. of } \\
\text { heteroresistant }\end{array}$ & $\begin{array}{l}\text { Prevalence } \\
(\%)(95 \% \\
\text { Cl) }\end{array}$ & $\mathrm{I}^{2}$ \\
\hline \multirow[t]{9}{*}{ Isoniazid } & Overall & & 19 & 11,761 & 1236 & $5(0-12)$ & 99.42 \\
\hline & Heteroresistance assay & Line-probe assay (LPA) & 16 & 10,266 & 1219 & $5(0-15)$ & 99.49 \\
\hline & & Sequencing-based methods & 2 & 1400 & 16 & $0(0-1)$ & - \\
\hline & & Other & 1 & 95 & 1 & $1(0-6)$ & - \\
\hline & Year & $2001-2014$ & 6 & 620 & 56 & $9(1-23)$ & 95.06 \\
\hline & & $2015-2017$ & 8 & 6035 & 43 & $2(0-5)$ & 93.29 \\
\hline & & $2018-2020$ & 5 & 5106 & 1137 & $4(0-27)$ & 99.71 \\
\hline & Quality & High & 7 & 4220 & 1175 & $9(0-27)$ & 99.02 \\
\hline & & Low & 12 & 7541 & 61 & $2(1-5)$ & 92.68 \\
\hline \multirow[t]{9}{*}{ Rifampin } & Overall & & 17 & 3782 & 600 & $7(2-14)$ & 97.59 \\
\hline & Heteroresistance assay & Line-probe assay (LPA) & 9 & 2511 & 526 & $9(2-20)$ & 97.43 \\
\hline & & Sequencing-based methods & 6 & 1001 & 71 & $6(0-16)$ & 96.02 \\
\hline & & Other & 2 & 270 & 3 & $1(0-2)$ & - \\
\hline & Year & $2001-2014$ & 6 & 808 & 102 & $12(3-26)$ & 95.84 \\
\hline & & 2015-2017 & 7 & 1269 & 28 & $2(1-4)$ & 65.52 \\
\hline & & $2018-2020$ & 4 & 1705 & 470 & $10(1-28)$ & 93.42 \\
\hline & Quality & High & 7 & 2479 & 506 & $9(1-23)$ & 98.49 \\
\hline & & Low & 10 & 1303 & 94 & $6(1-12)$ & 93.13 \\
\hline \multirow[t]{9}{*}{ Fluoroquinolones } & Overall & & 12 & 2153 & 113 & $10(3-19)$ & 96.20 \\
\hline & Heteroresistance assay & Line-probe assay (LPA) & 4 & 350 & 25 & $9(0-24)$ & 92.26 \\
\hline & & Sequencing-based methods & 7 & 1711 & 80 & $10(1-27)$ & 97.40 \\
\hline & & Other & 1 & 92 & 8 & $9(4-16)$ & - \\
\hline & Year & $2001-2014$ & 5 & 636 & 81 & $12(3-26)$ & 94.48 \\
\hline & & 2015-2017 & 4 & 181 & 22 & $11(1-29)$ & 86.59 \\
\hline & & 2018-2020 & 3 & 1336 & 10 & $5(0-22)$ & - \\
\hline & Quality & High & 6 & 401 & 38 & $10(5-18)$ & 74.92 \\
\hline & & Low & 6 & 1752 & 75 & $9(0-25)$ & 97.79 \\
\hline Ethambutol & Overall & & 4 & 1509 & 9 & $1(0-4)$ & 78.23 \\
\hline
\end{tabular}

$r^{2}$ the percentage of variance in a meta-analysis that shows study heterogeneity 
methods, and $1 \%$ (95\% CI 0-2) using other-methods (Table 1).

\section{Fluoroquinolones}

HR to FQs was reported in 12 studies, with a weighted pooled prevalence of $10 \%$ (CI 95\% 3-19; $\mathrm{I}^{2}=96.2 \%$ (among 2153 MTB isolates (Table 1). Sensitivity analysis was performed based on the quality of the articles, HR assay, and the year of the study. The results of sensitivity analysis based on the quality of articles showed complete homogeneity between the results in high quality studies $\left(\mathrm{I}^{2}=74.92 \%\right)$, and substantial heterogeneity in low quality articles $\left(\mathrm{I}^{2}=97.79 \%\right)$ (Table 1 , Additional file 1$)$. The prevalence of HR to FQs was found to be $12 \%$ (95\% CI 3-26) during 2001-2014, reaching to $11 \%$ (95\% CI 1-29) in 2015-2017, but dropping at 5\% in 2018-2020 (95\% CI 0-22) (Table 1; Additional file 1).

LPA ( $\mathrm{n}=4)$ and sequencing-based methods $(\mathrm{n}=7)$ were the most frequent HR methods. The prevalence of HR to FQs using LPA was 9\% (95\% CI 0-24), 10\% (95\% CI 1-27) using sequencing-based methods, and 9\% (95\% CI 4-16) using other-methods (Table 1).

\section{Ethambutol}

HR to EMB was reported in 4 studies, with a weighted pooled prevalence of $1 \%$ (95\% CI $=0.01-0.04)$ among 1509 MTB isolates; a substantial heterogeneity was $\mathrm{I}^{2}$ $=78.23 \%$ (Fig. 2).

\section{Discussion}

The prevalence of HR to INH, RIF, FQs, and EMB was the main outcome of this meta-analysis. INH, RIF, FQs, and EMB are included in the first and second line of TB therapy protocols. Development of monoresistance, MDR and specific HR in clinical isolates has been reported in previous studies $[1,57]$. HR is an initial step to change from susceptible to monoresistant and/or MDR [58]. All different resistant forms are responsible for treatment failure, thus a more comprehensive understanding of the emergence, spread, and methods for detection of $\mathrm{HR}$ is critical. Here HR is defined as the presence of susceptible and resistant strains in one sample, and can be detected by conventional phenotypic and genotypic drug susceptibility test-DST-[Lowenstein-Jensen (LJ)]. As expected, genotypic DST methods provide results with more sensitivity and reliability [58]. As previously defined, no standard methods for the detection of heteroresistant strains exist, therefore, different methods are applied for HR detection including phonotypical methods (Etest, the disc diffusion, and the population analysis profile (PAP) test, and molecular methods (LPA, sequencing, MTBDRplus, and iPLEX Gold assay). Etest and disc diffusion tests reflect poor specificity and sensitivity. The PAP test is reliable method but difficult to perform, due to high cost and labor intensity [12]. In contrast, molecular test is easier to perform. Nonetheless, Folkvardsen et al. [9] demonstrated that various methods have different sensitivity and Mycobacterium growth indicator tubes (MGIT) DST is the most sensitive method in detection of MTBDR and heteroresistant MTB. In all articles included in our study, molecular methods were applied for detection of HR (such, as LPA, sequencing, MTBDRplus, iPLEX Gold assay, and etc.) (Additional file 2). Analyzing the efficiency of different detection methods is so complicated and expensive. Therefore, the clear data on their efficiency is limited [9]. HR prevalence to RIF (7\%) did not differ significantly compared to INH (5\%). The prevalence of HR is varied among different studies. For example, the low prevalence of HR to INH and RIF (less than 1\%) was reported in some studies [25, 59, 60], while discordant results were shown by other studies (higher than 5\%) [12, 61, 62]. On the other side, a very high prevalence of HR to INH and RIF (20\%) in 35 clinical samples has been reported by Hofmann-Thiel et al. [57]. Same results were demonstrated by other studies $[63,64]$. The most significant factors related to the differences in HR prevalence may be variety in sample size and detection methods. Based on subgroup analysis in the current study, no rising or gradually decreasing of HR prevalence was observed in the last 20 years. Probably this is associated with improvements in the detection methods for HR isolates resulting in appropriate therapy protocols and satisfactory outcomes. FQs are bactericidal drugs against MTB, and known as a major member of therapy protocols against MDR and XDR isolates [23, 65]. But recently, the high prevalence of FQs-resistant TB has been detected which leads to treatment failure $[66,67]$. Results of our meta-analysis explain that the prevalence of HR to FQs (10\%) is higher in comparison to other investigated drugs, including INH, RIF, and EMB. Also, a high proportion of (20-38\%) HR to FQs has been observed in previous studies [54, 68-70]. However, discordant results were obtained by other researchers and a low proportion (about 1\%) of HR to FQs has also been reported $[4,71,72]$. Because of a very high proportion of HR or the risk of bias, we eliminated five articles in different subgroup analysis $[54,63,64,73,74]$. In fact, several factors are involved in this discrepancy in the proportion of $\mathrm{HR}$ among published studies. Firstly, study population and the origin of isolates (direct specimen or culture) can influence the HR diagnosis [75]. Secondly, only MDR/ XDR isolates or patients with treatment failure and relapses were included in some studies $[65,70]$. Thirdly, as previously mentioned, different methods possess varied sensitivity, thus the applied method is a major factor affecting the detection of HR [57]. Finally, geographic 


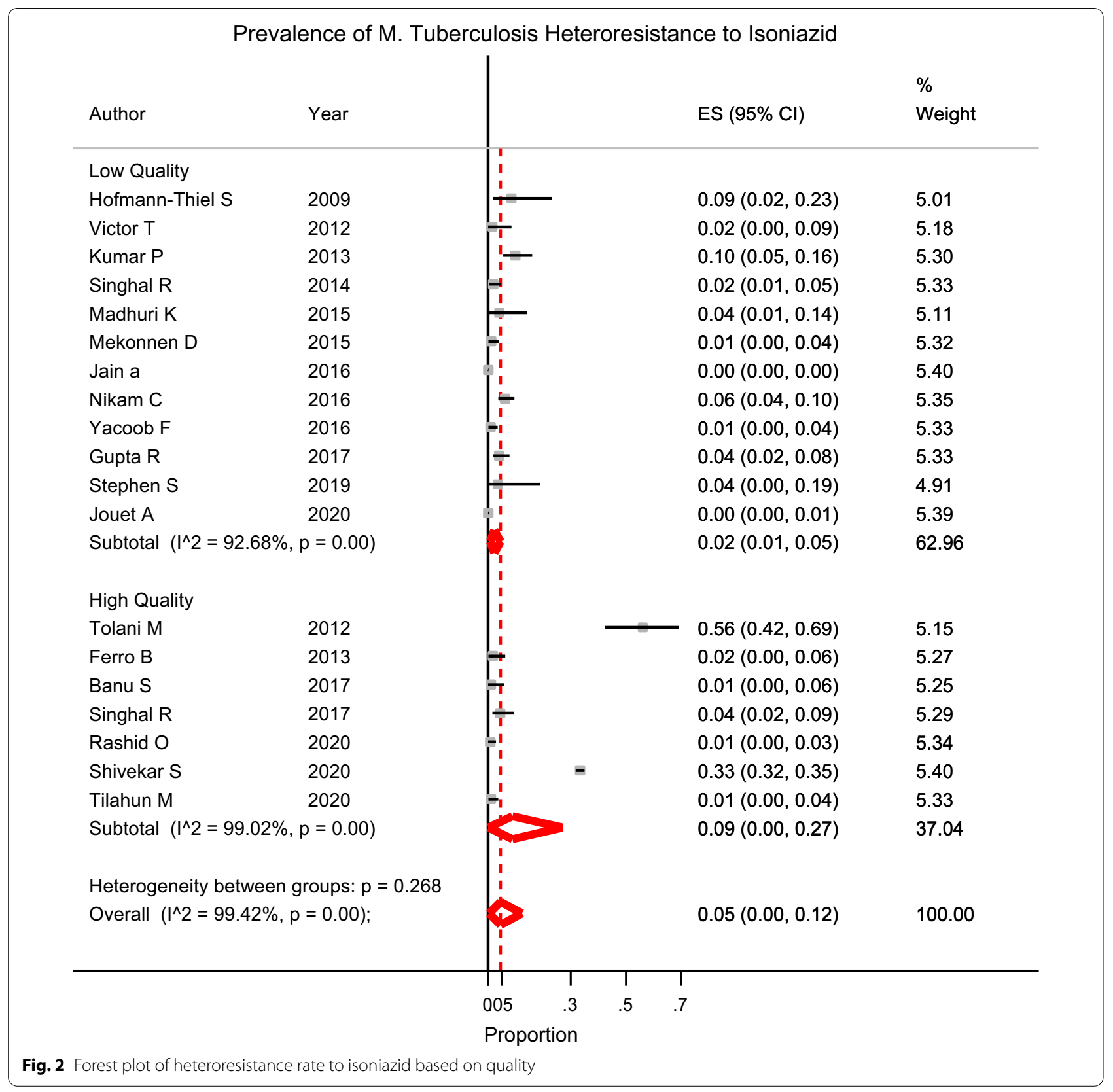

study area could be another factor, for example HR prevalence in particular regions like Uzbekistan and India is higher, because overall TB prevalence is higher in these regions $[57,75]$.

\section{Conclusion}

In summary, results obtained by this meta-analysis have provided a comprehensive insight on the proportion of $\mathrm{HR}$ to the main drugs employed against MTB isolates. Based on our analysis, HR in MTB isolates with different frequency rate is present worldwide. On the other hand,
$\mathrm{HR}$ is the main stage in the development of fully resistant isolates in TB patients. Therefore, to tackle this problem, the control of emerging resistance and also, decreasing antibiotics resistance rate, via fast and appropriate detection methods for HR diagnosis is crucial. Reliable HR detection method is an urgent need for selection of the correct therapy protocol and TB eradication.

\section{Abbreviations}

MTB: Mycobacterium tuberculosis; HR: Heteroresistance; TB: Tuberculosis; INH: Isoniazid; RIF: Rifampin; FQs: Fluoroquinolones; EMB: Ethambutol; XDR-TB: Extensively drug-resistant MTB; PRISMA: Preferred reporting items 
for systematic reviews and meta analyses guidelines; LPA: Line-probe assay; Cl: Confidence interval; PAP: Population analysis profile; MDR-TB: Multidrugresistant TB.

\section{Supplementary Information}

The online version contains supplementary material available at https://doi. org/10.1186/s12941-021-00478-z.

Additional file 1. Characteristics of included studies.

Additional file 2. Forest plots of antibiotic heteroresistance rate in $M$. tuberculosis isolates based on quality, publication year, and heteroresistant assay.

\section{Acknowledgements}

None.

\section{Authors' contributions}

MY, WY, KA, LM contributed to the conception, design, drafting, and analysis of the work. EK, AA, MY contributed in revising and final approval of the version to be published. All authors agreed and confirmed the manuscript for publication. All authors read and approved the final manuscript.

\section{Funding}

Not applicable in this section.

\section{Availability of data and materials}

All the data in this review are included in the manuscript.

\section{Declarations}

Ethics approval and consent to participate

Not applicable in this section.

\section{Consent for publication}

Not applicable in this section.

\section{Competing interests}

Authors declare that they have no competing interests.

\section{Author details}

${ }^{1}$ Department of Pharmacy, Clinical Pharmaceutics Room, Sichuan Science City Hospital, Mianyang 621000, China. ${ }^{2}$ Sichuan College of Traditional Chinese Medicine, Mianyang 621000, China. ${ }^{3}$ Department of Epidemiology, School of Public Health, Iran University of Medical Sciences, Tehran, Iran. ${ }^{4}$ Department of Clinical Microbiology, Sirjan School of Medical Sciences, P.O. Box 78169-16338, Sirjan, Iran. ${ }^{5}$ Laboratory Sciences Research Center, Golestan University of Medical Sciences, Gorgan, Iran. ${ }^{6}$ Department of Laboratory Sciences, Faculty of Paramedicine, Golestan University of Medical Sciences, Gorgan, Iran. ${ }^{7}$ Laboratory Sciences Research Center, Faculty of Paramedical Sciences, Golestan University of Medical Sciences, Negative Floor 1, Gorgan-Sari Road, P.O. Box: 4918936316, Gorgan, Golestan Province, Iran.

Received: 6 June 2021 Accepted: 5 October 2021

Published online: 13 October 2021

\section{References}

1. Anthwal D, Gupta RK, Bhalla M, Bhatnagar S, Tyagi JS, Haldar S. Direct detection of rifampin and isoniazid resistance in sputum samples from tuberculosis patients by high-resolution melt curve analysis. J Clin Microbiol. 2017;55(6):1755-66.

2. Operario DJ, Koeppel AF, Turner SD, Bao Y, Pholwat S, Banu S, Foongladda S, Mpagama S, Gratz J, Ogarkov O. Prevalence and extent of heteroresistance by next generation sequencing of multidrug-resistant tuberculosis. PLOS ONE. 2017;12(5):e0176522.
3. World Health Organization. Global tuberculosis report 2020: executive summary. Geneva:WHO; 2020.

4. Ajbani K, Nikam C, Kazi M, Gray C, Boehme C, Balan K, Shetty A, Rodrigues C. Evaluation of genotype MTBDRsl assay to detect drug resistance associated with fluoroquinolones, aminoglycosides and ethambutol on clinical sediments. PloS ONE. 2012;7(11):e49433.

5. Metcalfe JZ, Streicher E, Theron G, Colman RE, Penaloza R, Allender C, Lemmer D, Warren RM, Engelthaler DM. Mycobacterium tuberculosis subculture results in loss of potentially clinically relevant heteroresistance. Antimicrob Agents Chemother. 2017. https://doi.org/10.1128/AAC. 00888-17.

6. World Health Organization. Global tuberculosis report. Geneva: WHO; 2019.

7. Ng KC, Supply P, Cobelens FG, Gaudin C, Gonzalez-Martin J, de Jong BC, Rigouts $L$. How well do routine molecular diagnostics detect rifampin heteroresistance in Mycobacterium tuberculosis? J Clin Microbiol. 2019 https://doi.org/10.1128/JCM.00717-19.

8. Ley S, de Vos M, Van Rie A, Warren R. Deciphering within-host microevolution of Mycobacterium tuberculosis through whole-genome sequencing: the phenotypic impact and way forward. Microbiol Mol Biol Rev. 2019. https://doi.org/10.1128/MMBR.00062-18.

9. Folkvardsen DB, Thomsen VØ, Rigouts L, Rasmussen EM, Bang D, Bernaerts G, Werngren J, Toro JC, Hoffner S, Hillemann D. Rifampin heteroresistance in Mycobacterium tuberculosis cultures as detected by phenotypic and genotypic drug susceptibility test methods. J Clin Microbiol. 2013;51(12):4220-2.

10. Mclvor A, Koornhof H, Kana BD. Relapse, re-infection and mixed infections in tuberculosis disease. Pathog Dis. 2017. https://doi.org/10.1093/ femspd/ftx020.

11. Chen J, Huang F, Yin X, Gu D. Assessments of different methods for testing heteroresistance to rifampicin in tubercle bacillus. J Nanosci Nanotechnol. 2018;18(12):8414-8.

12. Andersson DI, Nicoloff $\mathrm{H}$, Hjort K. Mechanisms and clinical relevance of bacterial heteroresistance. Nat Rev Microbiol. 2019;17(8):479-96.

13. Srinivas P, Hunt LN, Pouch SM, Thomas K, Goff DA, Pancholi P, Balada-Llasat J-M, Bauer KA. Detection of colistin heteroresistance in Acinetobacter baumannii from blood and respiratory isolates. Diagn Microbiol Infect Dis. 2018;91(2):194-8.

14. Park K-H, Kim ES, Kim HS, Park S-J, Bang KM, Park HJ, Park S-Y, Moon SM, Chong YP, Kim S-H. Comparison of the clinical features, bacterial genotypes and outcomes of patients with bacteraemia due to heteroresistant vancomycin-intermediate Staphylococcus aureus and vancomycinsusceptible S. aureus. J Antimicrob Chemother. 2012;67(8):1843-9.

15. Fernández-Cuenca F, Gómez-Sánchez M, Rodríguez-Baño J, MartínezMartínez L, Vila J, Bou G, Pascual A. Epidemiological and clinical features associated with colonisation/infection by Acinetobacter baumannii with phenotypic heterogeneous resistance to carbapenems. Int J Antimicrob Agents. 2012;40(3):235-8.

16. Kang C, Kim Y, Jung S-I, Park W, Song K-H, Park K-H, Choe P, Jang H-C, Lee S, Kim Y-S. agr functionality affects clinical outcomes in patients with persistent methicillin-resistant Staphylococcus aureus bacteraemia. Eur J Clin Microbiol Infect Dis. 2017;36(11):2187-91.

17. Rigouts L, Miotto P, Schats M, Lempens P, Cabibbe A, Galbiati S, Lampasona $V$, De Rijk P, Cirillo D, de Jong B. Fluoroquinolone heteroresistance in Mycobacterium tuberculosis: detection by genotypic and phenotypic assays in experimentally mixed populations. Sci Rep. 2019;9(1):1-8.

18. Moher D, Liberati A, Tetzlaff J, Altman DG. med PGJP: Preferred reporting items for systematic reviews and meta-analyses: the PRISMA statement. PloS Med. 2009;6(7):e1000097.

19. Modesti PA, Reboldi G, Cappuccio FP, Agyemang C, Remuzzi G, Rapi S, Perruolo E, Parati G. Settings EWGoCRiLR: panethnic differences in blood pressure in Europe: a systematic review and meta-analysis. PloS ONE. 2016;11(1):e0147601

20. Eilertson B, Maruri F, Blackman A, Herrera M, Samuels DC. Sterling TRJAa, chemotherapy: High proportion of heteroresistance in gyrA and gyrB in fluoroquinolone-resistant Mycobacterium tuberculosis clinical isolates. Antimicrob Agents Chemother. 2014;58(6):3270-5.

21. Rinder H, Mieskes K, Löscher T. Disease L: heteroresistance in Mycobacterium tuberculosis. Int J Tuberc Lung Dis. 2001;5(4):339-45.

22. Banu S, Pholwat S, Foongladda S, Chinli R, Boonlert D, Ferdous SS, Rahman SMM, Rahman A, Ahmed S, Houpt ER. Performance of TaqMan array 
card to detect TB drug resistance on direct specimens. PLOS ONE. 2017. https://doi.org/10.1371/journal.pone.0177167.

23. Chakravorty S, Aladegbami B, Thoms K, Lee JS, Lee EG, Rajan V, Cho EJ, Kim H, Kwak H, Kurepina N, et al. Rapid detection of fluoroquinoloneresistant and heteroresistant Mycobacterium tuberculosis by use of sloppy molecular beacons and dual melting-temperature codes in a real-time PCR assay. J Clin Microbiol. 2011;49(3):932-40.

24. Chakravorty S, Kothari H, Aladegbami B, Cho EJ, Lee JS, Roh SS, Kim H, Kwak H, Lee EG, Hwang SH, et al. Rapid, high-throughput detection of rifampin resistance and heteroresistance in Mycobacterium tuberculosis by use of sloppy molecular beacon melting temperature coding. J Clin Microbiol. 2012. https://doi.org/10.1128/JCM.00143-12.

25. Chakravorty S, Roh SS, Glass J, Smith LE, Simmons AM, Lund K, Lokhov S, Liu X, Xu P, Zhang GL, et al. Detection of isoniazid-, fluoroquinolone-, amikacin-, and kanamycin-resistant tuberculosis in an automated, multiplexed 10-color assay suitable for point-of-care use. J Clin Microbiol. 2017;55(1):183-98.

26. Chakravorty S, Simmons AM, Rowneki M, Parmar H, Cao Y, Ryan J, Banada PP, Deshpande S, Shenai S, Gall A, et al. The new Xpert MTB/RIF ultra: improving detection of Mycobacterium tuberculosis and resistance to Rifampin in an assay suitable for point-of-care testing. mBio. 2017. https://doi.org/10.1128/mBio.00812-17.

27. Coeck N, de Jong BC, Diels M, de Rijk P, Ardizzoni E, Van Deun A, Rigouts L. Correlation of different phenotypic drug susceptibility testing methods for four fluoroquinolones in Mycobacterium tuberculosis. J Antimicrob Chemother. 2016. https://doi.org/10.1093/jac/dkv499.

28. Daum LT, Konstantynovska OS, Solodiankin OS, Liashenko OO, Poteiko PI, Bolotin VI, Hrek II, Rohozhyn AV, Rodriguez JD, Fischer GW, et al. Nextgeneration sequencing for characterizing drug resistance-conferring Mycobacterium tuberculosis genes from clinical isolates in the Ukraine. J Clin Microbiol. 2018. https://doi.org/10.1128/JCM.00009-18.

29. Eilertson B, Maruri F, Blackman A, Herrera M, Samuels DC, Sterling TR. High proportion of heteroresistance in gyr $A$ and gyrB in fluoroquinoloneresistant Mycobacterium tuberculosis clinical isolates. Antimicrob Agents Chemother. 2014;58(6):3270-5.

30. Ferro BE, García PK, Nieto LM, Van Soolingen D. Predictive value of molecular drug resistance testing of Mycobacterium tuberculosis isolates in Valle del Cauca. Colombia J Clin Microbiol. 2013. https://doi.org/10. 1128/JCM.00429-13.

31. Gupta R, Thakur R, Kushwaha S, Jalan N, Rawat P, Gupta P, Aggarwal A, Gupta M, Manchanda V. Isoniazid and rifampicin heteroresistant Mycobacterium tuberculosis isolated from tuberculous meningitis patients in India. Indian J Tuberc. 2018;65(1):52-6.

32. Heep M, Brandstatter B, Rieger U, Lehn N, Richter E, Rusch-Gerdes S, Niemann S. Frequency of rpoB mutations inside and outside the cluster I region in rifampin-resistant clinical Mycobacterium tuberculosis isolates. J Clin Microbiol. 2001;39(1):107-10.

33. Hofmann-Thiel S, van Ingen J, Feldmann K, Turaev L, Uzakova GT, Murmusaeva G, van Soolingen D, Hoffmann H. Mechanisms of heteroresistance to isoniazid and rifampin of Mycobacterium tuberculosis in Tashkent, Uzbekistan. Eur Respir J. 2009;33(2):368-74.

34. Huo F, Ma Y, Li S, Xue Y, Shang Y, Dong L, Li Y, Pang Y. Specific gyrA gene mutations correlate with high prevalence of discordant levofloxacin resistance in Mycobacterium tuberculosis isolates from Beijing, China. J Mol Diagn. 2020. https://doi.org/10.1016/j.jmoldx.2020.06.010.

35. Jain A, Singh PK, Chooramani G, Dixit P, Malhotra HS. Drug resistance and associated genetic mutations among patients with suspected MDR-TB in Uttar Pradesh, India. Int J Tuberc Lung Dis. 2016. https://doi.org/10.5588/ ijtld.15.0874.

36. Jouet A, Gaudin C, Badalato N, Allix-Béguec C, Duthoy S, Ferré A, Diels M, Laurent $Y$, Contreras S, Feuerriegel S, et al. Deep amplicon sequencing for culture-free prediction of susceptibility or resistance to 13 antituberculous drugs. Eur Respir J. 2020. https://doi.org/10.1183/13993003. 02338-2020.

37. Kumar P, Balooni V, Sharma BK, Kapil V, Sachdeva KS, Singh S. High degree of multi-drug resistance and hetero-resistance in pulmonary TB patients from Punjab state of India. Tuberculosis. 2014;94(1):73-80.

38. Lu W, Feng Y, Wang J, Zhu L. Evaluation of MTBDR plus and MTBDR sl in detecting drug-resistant tuberculosis in a Chinese population. Dis Markers. 2016. https://doi.org/10.1155/2016/2064765.
39. Madhuri K, Deshpande S, Dharmashale S, Bharadwaj R. Utility of line probe assay for the early detection of multidrug-resistant pulmonary tuberculosis. J Glob Infect Dis. 2015;7(2):60-5.

40. Mekonnen D, Admassu A, Mulu W, Amor A, Benito A, Gelaye W, Biadglegne F, Abera B. Multidrug-resistant and heteroresistant Mycobacterium tuberculosis and associated gene mutations in Ethiopia. Int $\mathrm{J}$ Infect Dis. 2015;39:34-8.

41. Molina-Moya B, Lacoma A, Prat C, Pimkina E, Diaz J, García-Sierra N, Haba L, Maldonado J, Samper S, Ruiz-Manzano J, et al. Diagnostic accuracy study of multiplex PCR for detecting tuberculosis drug resistance. J Infect. 2015. https://doi.org/10.1016/j.jinf.2015.03.011.

42. Nikam C, Patel R, Sadani M, Ajbani K, Kazi M, Soman R, Shetty A, Georghiou SB, Rodwell TC, Catanzaro A, et al. Redefining MTBDRplus test results: what do indeterminate results actually mean? Int J Tuberc Lung Dis. 2016;20(2):154-9.

43. Pietersen E, Peter J, Streicher E, Sirgel F, Rockwood N, Mastrapa B, Te Riele J, Davids M, van Helden P, Warren R, et al. High frequency of resistance, lack of clinical benefit, and poor outcomes in capreomycin treated South African patients with extensively drug-resistant tuberculosis. PIOS ONE. 2015;10(4):e0123655.

44. Plinke C, Cox HS, Kalon S, Doshetov D, Rüsch-Gerdes S, Niemann S. Tuberculosis ethambutol resistance: concordance between phenotypic and genotypic test results. Tuberculosis. 2009;89(6):448-52.

45. Rashid O, Farhana A, Bali N, Peer M, Kour R, Nasir R, Bashir Y. Early detection of multi-drug resistant tuberculosis and mutations in Mycobacterium tuberculosis isolates using line probe assay from a tertiary care centre in Northern India. J Clin Diagn Res. 2020;14(6):DC19-24.

46. Shivekar SS, Kaliaperumal V, Brammacharry U, Sakkaravarthy A, Raj CKV, Alagappan C, Muthaiah M. Prevalence and factors associated with multidrug-resistant tuberculosis in South India. Sci Rep. 2020;10(1):17552.

47. Singhal R, Arora J, Sah GC, Bhalla M, Sarin R, Prasad Myneedu V. Frequency of multi-drug resistance and mutations in Mycobacterium tuberculosis isolates from Punjab state of India. J Epidemiol Glob Health. 2017. https:// doi.org/10.1016/j.jegh.2017.05.002.

48. Singhal R, Myneedu VP, Arora J, Singh N, Sah GC, Sarin R. Detection of multi-drug resistance and characterization of mutations in Mycobacterium tuberculosis isolates from North-Eastern States of India using GenoType MTBDRplus assay. Indian J Med Microbiol. 2014. https://doi.org/10. 4103/0255-0857.150879.

49. Stephen S, Muzhizhizhi D, Dhibi N, Chidemo T, Samaneka W, Matubu TA, Hakim JG, Chirenje ZM. Validation of the GenoType ${ }^{\circledR}$ MTBDRplus Ver 2.0 assay for detection of rifampicin and isoniazid resistance in Mycobacterium tuberculosis complex isolates at UZCHS-CTRC TB research laboratory. Int J Mycobacteriol. 2019. https://doi.org/10.4103/ijmy.ijmy_170_18.

50. Tilahun M, Shimelis E, Wogayehu T, Assefa G, Wondimagegn G, Mekonnen A, Hailu T, Bobosha K, Aseffa A. Molecular detection of multidrug resistance pattern and associated gene mutations in $M$. tuberculosis isolates from newly diagnosed pulmonary tuberculosis patients in Addis Ababa, Ethiopia. PloS ONE. 2020;15(8):e0236054.

51. Tolani MP, D'Souza DTB, Mistry NF. Drug resistance mutations and heteroresistance detected using the GenoType MTBDRplus assay and their implication for treatment outcomes in patients from Mumbai, India. BMC Infect Dis. 2012. https://doi.org/10.1186/1471-2334-12-9.

52. Victor TC, Van Helden PD, Warren R. Prediction of drug resistance in $M$. tuberculosis: molecular mechanisms, tools, and applications. IUBMB Life. 2002. https://doi.org/10.1080/15216540212642.

53. Yacoob FL, Jose BP, Lelitha SDK, Sreenivasan S. Primary multidrug resistant tuberculosis and utility of line probe assay for its detection in smear-positive sputum samples in a tertiary care hospital in South India. J Pathog. 2016. https://doi.org/10.1155/2016/6235618.

54. Zhang X, Zhao B, Liu L, Zhu Y, Zhao Y, Jin Q. Subpopulation analysis of heteroresistance to fluoroquinolone in Mycobacterium tuberculosis isolates from Beijing, China. J Clin Microbiol. 2012;50(4):1471-4.

55. Zhang XB, Zhao B, Huang HR, Zhu YF, Peng JP, Dai GM, Jiang GL, Liu LG, Zhao YL, Jin Q. Co-occurrence of amikacin-resistant and -susceptible Mycobacterium tuberculosis isolates in clinical samples from Beijing, China. J Antimicrob Chemother. 2013;68(7):1537-42.

56. Zheng C, Li S, Luo Z, Pi R, Sun H, He Q, Tang K, Luo M, Li Y, Couvin D. Mixed infections and rifampin heteroresistance among Mycobacterium tuberculosis clinical isolates. J Clin Microbiol. 2015;53(7):2138-47. 
57. Hofmann-Thiel S, van Ingen J, Feldmann K, Turaev L, Uzakova GT, Murmusaeva G, van Soolingen D, Hoffmann H. Mechanisms of heteroresistance to isoniazid and rifampin of Mycobacterium tuberculosis in Tashkent, Uzbekistan. Eur Respir J. 2009;33(2):368-74.

58. Yacoob FL, Philomina Jose B, Karunakaran Lelitha SD, Sreenivasan S. Primary multidrug resistant tuberculosis and utility of line probe assay for its detection in smear-positive sputum samples in a tertiary care hospital in South India. J Pathog. 2016. https://doi.org/10.1155/2016/6235618.

59. Banu S, Pholwat S, Foongladda S, Chinli R, Boonlert D, Ferdous SS, Rahman SM, Rahman A, Ahmed S, Houpt ER. Performance of TaqMan array card to detect TB drug resistance on direct specimens. PloS ONE. 2017;12(5):e0177167.

60. Jain A, Singh P, Chooramani G, Dixit P, Malhotra H. Drug resistance and associated genetic mutations among patients with suspected MDR-TB in Uttar Pradesh, India. Int J Tuberc Lung Dis. 2016;20(7):870-5.

61. Daum L, Konstantynovska O, Solodiankin O, Liashenko O, Poteiko P, Bolotin V, Hrek I, Rohozhyn A, Rodriguez J, Fischer G. Next-generation sequencing for characterizing drug resistance-conferring Mycobacterium tuberculosis genes from clinical isolates in the Ukraine. J Clin Microbiol. 2018. https://doi.org/10.1128/JCM.00009-18

62. Nikam C, Patel R, Sadani M, Ajbani K, Kazi M, Soman R, Shetty A, Georghiou SB, Rodwell TC, Catanzaro A. Redefining MTBDRplus test results: what do indeterminate results actually mean? Int J Tuberc Lung Dis. 2016;20(2):154-9.

63. Tolani MP, D'souza DTB, Mistry NF. Drug resistance mutations and heteroresistance detected using the GenoType MTBDR plus assay and their implication for treatment outcomes in patients from Mumbai, India. BMC Infect Dis. 2012;12(1):1-8.

64. Shivekar SS, Kaliaperumal V, Brammacharry U, Sakkaravarthy A, Raj CV Alagappan C, Muthaiah M. Prevalence and factors associated with multidrug-resistant tuberculosis in South India. Sci Rep. 2020;10(1):1-11.

65. Huo F, Ma Y, Li S, Xue Y, Shang Y, Dong L, Li Y, Pang Y. Specific gyrA gene mutations correlate with high prevalence of discordant levofloxacin resistance in Mycobacterium tuberculosis isolates from Beijing, China. J Mol Diagn. 2020;22(9):1199-204.

66. Umubyeyi AN, Rigouts L, Shamputa IC, Fissette K, Elkrim Y, De Rijk P, Struelens M, Portaels F. Limited fluoroquinolone resistance among Mycobacterium tuberculosis isolates from Rwanda: results of a national survey. J Antimicrob Chemother. 2007;59(5):1031-3.
67. Xu P, Li X, Zhao M, Gui X, DeRiemer K, Gagneux S, Mei J, Gao Q. Prevalence of fluoroquinolone resistance among tuberculosis patients in Shanghai, China. J Antimicrob Chemother. 2009;53(7):3170-2.

68. An DD, Duyen NTH, Lan NTN, Ha DTM, Kiet VS, Chau NV, Dung NH, Sy DN, Farrar J, Caws M. Beijing genotype of Mycobacterium tuberculosis is significantly associated with high-level fluoroquinolone resistance in Vietnam. Antimicrob Agents Chemother. 2009;53(11):4835-9.

69. Campbell PJ, Morlock GP, Sikes RD, Dalton TL, Metchock B, Starks AM, Hooks DP, Cowan LS, Plikaytis BB, Posey JE. Molecular detection of mutations associated with first-and second-line drug resistance compared with conventional drug susceptibility testing of Mycobacterium tuberculosis. Antimicrob Agents Chemother. 2011;55(5):2032-41.

70. Baffoe-Bonnie A, Houpt ER, Turner L, Dodge D, Heysell SK. Drug-susceptible and multidrug-resistant Mycobacterium tuberculosis in a single patient. Emerg Infect Dis. 2019;25(11):2120.

71. Ferro BE, García PK, Nieto LM, van Soolingen D. Predictive value of molecular drug resistance testing of Mycobacterium tuberculosis isolates in Valle del Cauca, Colombia. J Clin Microbiol. 2013;51 (7):2220-4.

72. Jouet A, Gaudin C, Badalato N, Allix-Béguec C, Duthoy S, Ferré A, Diels M, Laurent $Y$, Contreras $S$, Feuerriegel S. Deep amplicon sequencing for culture-free prediction of susceptibility or resistance to 13 anti-tuberculous drugs. Eur Respir J. 2021. https://doi.org/10.1183/13993003.02338-2020.

73. Kumar P, Balooni V, Sharma BK, Kapil V, Sachdeva K, Singh S. High degree of multi-drug resistance and hetero-resistance in pulmonary TB patients from Punjab state of India. Tuberculosis. 2014;94(1):73-80.

74. Lu W, Feng Y, Wang J, Zhu L. Evaluation of MTBDRplus and MTBDRs in detecting drug-resistant tuberculosis in a Chinese population. Dis Markers. 2016. https://doi.org/10.1155/2016/2064765.

75. Mekonnen D, Admassu A, Mulu W, Amor A, Benito A, Gelaye W, Biadglegne F, Abera B. Multidrug-resistant and heteroresistant Mycobacterium tuberculosis and associated gene mutations in Ethiopia. Int J Infect Dis. 2015;39:34-8.

\section{Publisher's Note}

Springer Nature remains neutral with regard to jurisdictional claims in published maps and institutional affiliations.
Ready to submit your research? Choose BMC and benefit from:

- fast, convenient online submission

- thorough peer review by experienced researchers in your field

- rapid publication on acceptance

- support for research data, including large and complex data types

- gold Open Access which fosters wider collaboration and increased citations

- maximum visibility for your research: over $100 \mathrm{M}$ website views per year

At BMC, research is always in progress.

Learn more biomedcentral.com/submissions 